\title{
Obtenção de extratos secos de carotenoides a partir da biomassa da microalga Haematococcus pluvialis por secagem em torre de aspersão (spray-drying)
}

\author{
Obtaining dried extracts from the biomass of the \\ microalga Haematococcus pluvialis by spray \\ drying
}

Gecioni Loch-Neckel ${ }^{1}$, Francine Elisabeth Schütz ${ }^{1}$, Roberto Bianchini Derner ${ }^{2}$, Elenara Lemos-Senna ${ }^{1}$

\begin{abstract}
${ }^{1}$ Departamento de Ciências Farmacêuticas, Centro de Ciências da Saúde, Universidade Federal de Santa Catarina, 88040-900, Florianópolis, Santa Catarina, Brasil.

${ }^{2}$ Departamento de Aquicultura - Centro de Ciências Agrárias, Universidade Federal de Santa Catarina, 88040-900, Florianópolis, Santa Catarina, Brasil.

e-mail: gneckel@hotmail.com, francineschutz@yahoo.com.br, lemos.senna@ufsc.br, robertoderner@lcm.ufsc.br
\end{abstract}

\section{RESUMO}

Os carotenoides compreendem uma classe de mais de 600 pigmentos naturais, cujo potencial biológico está relacionado à sua atividade antioxidante, regulação do crescimento celular, modulação da resposta imune e da atividade anti-inflamatória. A Haematococcus pluvialis é uma microalga verde, conhecida por sintetizar e acumular grandes quantidades de carotenoides, entre estes a astaxantina. Este trabalho teve como objetivo preparar e caracterizar extratos secos de $\mathrm{H}$. pluvialis pela técnica de secagem em torre de aspersão, avaliando o efeito do emprego de adjuvantes farmacêuticos e dos parâmetros de secagem sobre as características finais dos extratos secos. Além disso, as atividades antioxidante e citotóxica dos carotenoides obtidos a partir dos extratos secos foram avaliadas. Quando a extração dos carotenoides a partir da biomassa da microalga foi avaliada, altos valores de rendimento que variaram entre $87,8 \%$ e $94,6 \%$ foram obtidos. Após a extração e a secagem por pulverização não foram observadas diferenças na morfologia das partículas e os valores de densidade aparente e compactada não parecem ser afetados quando as diferentes condições de secagem por pulverização foram testadas. Observou-se que o aumento da temperatura e concentração do adjuvante de secagem proporcionou redução do teor de carotenoides totais. Os valores da atividade antioxidante dos extratos de carotenoides variaram entre 55,78 e 77,83\%, com os menores valores verificados para os extratos secos preparados com a maior temperatura de entrada. A avaliação da atividade antiproliferativa dos extratos de carotenoides demonstrou que as maiores concentrações testadas reduziram de 66,58 e $82,91 \%$ a viabilidade de células de melanoma murino B16F10. Assim, o conjunto de resultados demonstrou que a obtenção de extratos secos a partir da biomassa de Haematococcus pluvialis visando a produção de matérias-primas farmacêuticas utilizando a secagem em torre de aspersão (spray dryer) é promissor especialmente, com altos valores de carotenoides totais e sem perda significativa da atividade antioxidante.

Palavras-chave: carotenoides, microalgas, secagem por pulverização, astaxantina, antioxidantes.

\section{ABSTRACT}

Carotenoids comprise a class of more than 600 natural pigments whose biological potential is related to their antioxidant activity, regulation of cell growth, modulation of the immune response and antiinflammatory activity. Haematococcus pluvialis is a green microalga known to synthesize and accumulate large amounts of carotenoids, among them astaxanthin. The objective of this work was to prepare and characterize dry extracts of $\mathrm{H}$. pluvialis by spray drying technique, evaluating the effect of the use of pharmaceutical adjuvants and the drying parameters on the final characteristics of dry extracts. In addition, the antioxidant and cytotoxic activities of the carotenoids obtained from the dried extracts were evaluated. When the extraction of the carotenoids from the microalgae biomass was evaluated, high yield values ranging from $87.8 \%$ to $94.6 \%$ were obtained. After extraction and spray drying no differences in particle morphology were observed and bulk density and compacted values did not appear to be affected when different spray drying conditions were tested. It was observed that increasing the temperature and 
concentration of the drying aid provided a reduction in the total carotenoid content. The antioxidant activity values of carotenoid extracts varied between 55.78 and $77.83 \%$, with the lowest values observed for the dry extracts prepared with the highest inlet temperature. The evaluation of the antiproliferative activity of carotenoid extracts showed that the highest concentrations tested reduced the viability of B16F10 murine melanoma cells from 66.58 and $82.91 \%$. Thus, the results set showed that the extraction of dry extracts from the biomass of Haematococcus pluvialis for the production of pharmaceutical raw materials using spray drying is especially promising, with high total carotenoid values, and without significant loss of antioxidant activity.

Keywords: carotenoids, microalgae, spray drying, astaxanthin, antioxidant.

\section{INTRODUÇÃO}

Os carotenoides compreendem uma classe de mais de 600 pigmentos naturais amplamente distribuídos na natureza, cuja coloração varia do amarelo ao vermelho intenso [1]. O potencial biotecnológico está fortemente relacionado a sua atividade antioxidante, pois têm a capacidade de agir no sequestro de radicais livres e inativação dos mesmos [2]. Além dos efeitos antioxidantes, estudos têm mostrado que os carotenoides podem atuar na regulação do crescimento celular, modulação da expressão gênica, da resposta imune e da atividade anti-inflamatória [3] [1].

A Haematococcus pluvialis é uma microalga verde pertencente à divisão Chlorophyta, conhecida por sintetizar e acumular grandes quantidades de carotenoides, sob condições ambientais extremas como alta intensidade luminosa ou condições oligotróficas. Entre os carotenoides produzidos por esta microalga, pode-se destacar a astaxantina (3,39-dihidroxi-b,b-caroteno-4,49-diona) [4]. A configuração química diferenciada faz com que a astaxantina exiba diversos efeitos biológicos na prevenção e/ou tratamento de doenças como diabetes [5], câncer [6], doenças inflamatórias [7] [8], e doenças cardiovasculares [9] [10], e atividade fotoprotetora [11] [12].

Devido a sua capacidade de produzir elevadas quantidades de carotenoides, Haematococcus pluvialis é uma microalga que apresenta grande interesse para o setor farmacêutico e cosmético. Entretanto, para uso farmacêutico é conveniente a obtenção de matérias-primas com características que permitam a sua transformação em formas farmacêuticas, incluindo a padronização em termos de concentração de constituintes ativos, maior estabilidade química, físico-química e microbiológica, fácil padronização e facilidade de manipulação [13] [14] [15]. Neste sentido, a solução mais óbvia e que atende a todos estes requisitos é a secagem dos extratos obtidos a partir da biomassa desta microalga.

A escolha por métodos de secagem depende da escala de produção, das propriedades e da aplicação do produto que necessita ser seco. A liofilização e a secagem por pulverização (spray-drying) são as técnicas mais utilizadas para produtos de alto valor nutricional ou de valor agregado [16]. A secagem permite não somente a remoção de água, minimizando o crescimento microbiano e deterioração por meio de reações químicas, mas também a redução de peso e do volume, tornando assim o recipiente de acondicionamento mais barato e conveniente para o transporte e armazenamento. No que se refere à obtenção de extratos secos a partir de plantas, a secagem por spray drying é vantajosa pois além de permitir a obtenção de produtos secos, é uma técnica rápida, pouco agressiva ao produto, de baixo custo e elevado rendimento, além de possibilitar o controle da uniformidade e tamanho de partícula, e ainda gerar produtos intermediários com propriedades tecnológicas adequadas para a produção de medicamentos [14] [15]. Um ponto importante, no entanto, é que a composição bioquímica e, assim, o valor nutricional pode ser alterados por meio da técnica de secagem e armazenagem. Trabalhos publicados demonstraram que a secagem em torre de aspersão pode ser empregada na obtenção de extratos a partir da biomassa de microalgas, sem uma degradação excessiva dos carotenoides [17] [18] [19] [20]. Entretanto, estudos para obtenção de extratos secos ricos em carotenoides de $H$. pluvialis não estão descritos na literatura, tampouco envolvendo a caracterização deste produto tecnológico. Neste contexto, este trabalho teve como objetivo preparar e caracterizar extratos secos de $H$. pluvialis pela técnica de secagem em torre de aspersão e caracterizar estes extratos quanto ao efeito do emprego de adjuvantes farmacêuticos e dos parâmetros de secagem sobre as características finais dos extratos secos. Além disso, foram avaliadas as atividades antioxidante e citotóxica dos carotenoides obtidos a partir dos extratos secos. 


\section{MATERIAIS E MÉTODOS}

\subsection{Materiais Empregados}

A biomassa de Haematococcus pluvialis foi proveniente do produto comercial ALGAMAC AST (Aquafauna Bio-Marine, Hawthorne, EUA). DPPH (2,2-Difenil-1-picrilhidrazil), MTT (brometo de 3(4,5-dimetiltiazol-2-il)-2,5-difenil tetrazolio), DMSO (dimetilsufóxido) e o padrão de astaxantina foram adquiridos da Sigma-Aldrich (EUA). A biomassa de Haematococcus pluvialis foi obtida da Algamac AST (Aquafauna Bio-Marine, Hawthorne, EUA). O dióxido de silício coloidal (Aerosil®) foi adquirido da Pharmanostra (Brasil). Ácido clorídrico (P.A.), éter de petróleo (P.A.) e lauril sulfato de sódio e acetona (P.A.) foram todos adquiridos da Vetec, (Brasil). Acetonitrila grau HPLC e metanol grau HPLC foram obtidos da Tedia Brasil (Brasil).

\subsection{Preparação da solução extrativa de Haematococcus pluvialis}

A preparação da solução extrativa de Haematococcus pluvialis (SEHP) foi realizada empregando o método clássico de extração de carotenoides, conforme descrito por MEZZOMO et al. [21]. Brevemente, foram pesados $5 \mathrm{~g}$ da biomassa seca de $\mathrm{H}$. pluvialis e adicionados $200 \mathrm{~mL}$ de uma mistura de éter de petróleo:acetona:água $(15: 75: 10, \mathrm{v} / \mathrm{v} / \mathrm{v})$. A mistura foi mantida sob agitação magnética por 24 horas a 5 ${ }^{\circ} \mathrm{C}$ e protegida da luz. Após esse período, a mistura foi centrifugada a $2500 \mathrm{rpm}$ (Centrífuga Novatécnica® NT 810) durante 5 min e o sobrenadante coletado. Esta operação foi realizada 4 vezes, com o objetivo de extrair a maior quantidade possível de carotenoides, resultando em volume final de 800 mL. O sobrenadante foi coletado e denominado de solução extrativa de H. pluvialis (SEHP).

\subsection{Caracterização da solução extrativa de Haematococcus pluvialis}

Para a determinação do resíduo seco, $10 \mathrm{~g}$ da solução extrativa foram pesados em pesa filtros previamente tarados e submetidos à evaporação até secura em banho-maria. Os pesa filtros foram colocados em estufa em temperatura de $105{ }^{\circ} \mathrm{C}$, resfriados em dessecador e pesados até obtenção de peso constante. A determinação do $\mathrm{pH}$ da solução extrativa foi realizada em potenciômetro previamente calibrado. A medida da densidade relativa ( $(2020)$ da SEHP foi realizada com auxílio de um picnômetro de $25,0 \mathrm{~mL}$, previamente calibrado. O picnômetro foi preenchido com a SEHP e, em seguida, pesado. A densidade relativa foi então calculada como sendo a razão entre a massa da amostra (SEHP) e a massa de água, medidas na mesma temperatura. Todas as análises foram realizadas em triplicata.

\subsection{Determinação de carotenoides totais da solução extrativa}

A determinação dos carotenoides totais $(\mathrm{CT}, \mu \mathrm{g} / \mathrm{mL})$ da solução extrativa foi realizada por método espectrofotométrico. Brevemente, uma alíquota de $1,0 \mathrm{~mL}$ da solução extrativa foi transferida para um balão e submetida à evaporação sob pressão reduzida em evaporador rotatório, para eliminação do solvente. O resíduo foi então dissolvido em acetona e analisado no comprimento de onda de 320 a $700 \mathrm{~nm}$ em espectrofotômetro UV/VIS 1800 (Shimadzu, Japão). O valor dos carotenoides totais da SEHP foi calculado utilizando a equação 1, descrita por Davies (1976) [22]:

$C T=\underline{A \times 25}$

Em que A é a absorbância da amostra, 25 é o volume do solvente, $\varepsilon$ é o coeficiente de extinção específica da astaxantina em acetona ou $2198\left(100 \mathrm{~mL} \mathrm{~g}^{-1} \mathrm{~cm}^{-1}\right)$ e 100 é o peso da amostra. As análises foram realizadas em triplicata.

\subsection{Preparação dos Extratos Secos de Haematococcus pluvialis por Aspersão em Torre de Secagem (Spray-Drying)}

Para obtenção dos extratos secos de Haematococcus pluvialis (ES), $400 \mathrm{~mL}$ da solução extrativa SEHP foram submetidos à evaporação sob pressão reduzida até completa remoção do solvente orgânico. $\mathrm{O}$ resíduo foi então ressuspenso em $400 \mathrm{~mL}$ de água destilada para obtenção de uma suspensão aquosa de $H$. 
pluvialis. À esta suspensão aquosa foi adicionado dióxido de silício coloidal (Aerosil@ 200), lentamente, sob agitação constante, durante 30 minutos. A dispersão foi seca em um mini spray-dryer Buchi B-191 (Suíça). Os extratos secos foram coletados e pesados. Neste estudo, foram avaliados os efeitos da temperatura de entrada $\left(150{ }^{\circ} \mathrm{C}\right.$ ou $\left.175{ }^{\circ} \mathrm{C}\right)$ e da concentração de dióxido de silício coloidal $(2 \%$, $4 \%$ e $6 \%, \mathrm{~m} / \mathrm{V})$ sobre as características finais dos extratos secos, resultando na obtenção de 6 diferentes extratos secos. As condições de secagem empregadas estão mostradas na Tabela 1.

Tabela 1: Condições de secagem utilizadas para obtenção dos extratos secos de $H$. pluvialis utilizando fluxo de dispersão de $4 \mathrm{~mL} / \mathrm{min}$ e aspiração de $100 \%$.

\begin{tabular}{l|l|l|l|l|l|l}
\hline PARÂMETROS ANALISADOS & ESI & ES2 & ES3 & ES4 & ES5 & ES6 \\
\hline Temperatura de entrada $\left({ }^{\circ} \mathrm{C}\right)$ & 150 & 150 & 150 & 175 & 175 & 175 \\
\hline Temperatura de saída $\left({ }^{\circ} \mathrm{C}\right)$ & 40 & 40 & 40 & 60 & 60 & 60 \\
\hline Concentração de Aerosil $200 *(\%)$ & 2 & 4 & 6 & 2 & 4 & 4 \\
\hline
\end{tabular}

* Em relação ao volume total da dispersão.

\subsection{Caracterização dos extratos secos}

O rendimento bruto da operação de secagem foi estimado como sendo a diferença percentual entre a massa teórica de sólidos totais presente na suspensão de alimentação e a massa de extrato seco obtida. Os sólidos totais correspondem ao teor de resíduo seco da solução extrativa (SEHP), somada à massa de adjuvante adicionada, considerando o teor de umidade residual. A umidade residual dos extratos secos de H. pluvialis foi determinada pela metodologia de Karl Fischer em um titulador Karl Fischer modelo DL31 (Mettler Toledo, EUA). As análises foram realizadas em triplicata e os resultados expressos em percentagem de umidade residual $(\%, \mathrm{~m} / \mathrm{m})$. A distribuição granulométrica dos extratos secos de $H$. pluvialis foi determinada por difratometria a laser utilizando um analisador de partículas Mastersizer 2000 (Malvern Instruments, Reino Unido), com luz monocromática vermelha (632nm) de um laser de $\mathrm{He} \mathrm{Ne}$, com obscurecimento entre 10 e 13\%. Para as análises, cerca de $30 \mathrm{mg}$ dos extratos secos foram previamente dispersos em glicerina. As análises foram realizadas em triplicata. A distribuição do tamanho de partícula foi determinada com base na teoria de difração de Franhöffer e expressa em diâmetro por volume equivalente a 10 (d10\%), 50 (d50\%) e 90 (d90\%) do volume acumulado e diâmetro médio (d4,3), assim como pelo valor de Span. A morfologia das partículas dos extratos secos foi avaliada por microscopia eletrônica de varredura (MEV) em Microscópio Jeol JSM-6390LV (LCME/UFSC), com voltagem de $10 \mathrm{kV}$. A amostra foi fixada em porta-amostra (stubs) e recoberta com uma fina camada de ouro/paládio, utilizando-se uma recobridora à vácuo Bal-tec SCD005 (BAL-TEC AG, Liechtenstein).

\subsection{Determinação de carotenoides totais nos extratos secos}

A determinação dos carotenoides totais (CT) nos extratos secos foi realizada por método espectrofotométrico. Foi pesado $0,1 \mathrm{~g}$ de cada um dos extratos secos as amostras foram transferidas para balões volumétricos de $25,0 \mathrm{~mL}$ e o volume foi completado para $25 \mathrm{~mL}$ com acetona. As misturas resultantes foram centrifugadas e o sobrenadante foi coletado e analisado em espectrofotômetro UV/VIS (Shimadzu, Japão), em comprimento de onda de $460 \mathrm{~nm}$, usando acetona como branco. O teor de carotenoides totais no extrato seco $(\mathrm{g} / 100 \mathrm{~g})$ foi calculado conforme a equação 2 :

$C T=A \times 3 \times 25 \varepsilon \times m \times 100$

\subsection{Avaliação do perfil de dissolução dos carotenoides totais a partir dos extratos secos}

O perfil de dissolução dos carotenoides totais a partir dos extratos secos de H. pluvialis foi avaliado em aparelho de dissolução Nova Ética 299, acoplado ao aparato USP II (pá), contendo $200 \mathrm{~mL}$ de solução aquosa de lauril sulfato de sódio $0,5 \%(\mathrm{~m} / \mathrm{V})$, e mantido sob agitação constante a 75 rpm e temperatura de $37^{\circ} \mathrm{C}$. Para os ensaios, $200 \mathrm{mg}$ de extrato seco foram colocados em cápsulas de gelatina dura, sendo observada a manutenção das condições sink. Em intervalos de tempo pré-determinados, foram coletadas 
alíquotas de $5 \mathrm{~mL}$ do meio de dissolução e analisadas quanto ao teor de carotenoides totais por espectrofotometria de absorção no comprimento de onda de $460 \mathrm{~nm}$. Após cada coleta, o volume removido foi reposto com o meio de dissolução fresco. A precisão do método analítico (repetibilidade) foi determinada pela análise de seis amostras e expressa por meio do desvio padrão relativo (DPR\%) [23]. A partir dos resultados, foram construídas curvas de percentual de carotenoides totais liberado versus tempo (min). A eficiência de dissolução (ED\%) foi estimada através da seguinte equação 3:

$E D(\%)=\underline{A S C} \times 100$

Onde, ASC é a área sob a curva do perfil de dissolução calculada pelo método trapezoidal e ATR é a área total do retângulo, definido pela ordenada (100\% de dissolução).

\subsection{Avaliação da atividade antioxidante in vitro da biomassa, SEHP e dos extratos secos pelo método do DPPH}

A capacidade da biomassa de $H$. pluvialis em sequestrar o radical livre 1,1-difenil-2-picril-hidrazil (DPPH) foi avaliada conforme método descrito por CHEN et al. [24]. Para isso uma alíquota de $290 \mu \mathrm{L}$ da solução metanólica de DPPH $0,1 \mathrm{mM}$ foi adicionada a $10 \mu \mathrm{L}$ da SEHP e das soluções obtidas a partir dos extratos secos na concentração de $10 \mathrm{mg} / \mathrm{mL}$. As misturas foram agitadas e a placa foi deixada em repouso e ao abrigo da luz por 30 min. Posteriormente, a absorbância das amostras foi medida usando leitora de Elisa Automatica (TermoPlate®) a $530 \mathrm{~nm}$. O resultado final foi expresso em percentual de inibição, calculado de acordo com a equação 4:

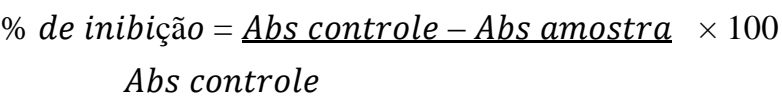

Onde, Abs controle é a absorbância obtida para o controle (solução de DPPH sem antioxidante) e Abs amostra é a absorbância obtida após leitura da amostra, na presença do DPPH.

\subsection{Avaliação da atividade citotóxica de extrato obtido a partir dos extratos secos}

Extratos obtidos a partir dos extratos secos de $H$. pluvialis foram avaliados quanto à sua capacidade citotóxica frente à linhagem de células de melanoma murino B16F10, através do método de MTT [25]. Este ensaio é um método que analisa a viabilidade e o estado metabólico da célula, baseado na conversão do sal 3-(4,5-dimetil-2-tiazol)-2,5-difenil-brometo de tetrazolium (MTT) em azul de formazan, a partir de enzimas mitocondriais presentes somente nas células metabolicamente ativas. As células B16F10 foram cultivadas em meio DMEM suplementado com $10 \%$ de soro fetal bovino, $2 \mathrm{mM}$ de glutamina e $1 \%$ de antibióticos (100 U/mL de penicilina e $100 \mu \mathrm{g} / \mathrm{mL}$ de estreptomicina), a $37^{\circ} \mathrm{C}$, em atmosfera com $5 \%$ de $\mathrm{CO}_{2}$ e $95 \%$ de umidade. As amostras dos extratos secos (ES1) solubilizadas em DMSO puro e estéril na concentração estoque de $4 \mathrm{mM} / \mathrm{mL}$ foram diluídas seriadamente em meio DMEM $(0,005-5 \mu \mathrm{M} / \mathrm{mL}) \mathrm{e}$ adicionadas a placas de 96 poços $(100 \mu \mathrm{L}$ /poço $)$ contendo as células previamente plaqueadas $\left(1 \times 10^{3}\right.$ células/poço). Depois de $72 \mathrm{~h}$ e $96 \mathrm{~h}$ de incubação em estufa a $37{ }^{\circ} \mathrm{C}$ e $5 \%$ de $\mathrm{CO}_{2}$, as placas foram centrifugadas, o sobrenadante aspirado e foram adicionados $100 \mathrm{uL}$ de MTT $(0,5 \mathrm{mg} / \mathrm{mL})$ por poço. Após incubação a $37^{\circ} \mathrm{C}$ por $3 \mathrm{~h}$, as placas foram novamente centrifugadas e aspiradas. $\mathrm{O}$ precipitado foi ressuspendido em $200 \mu \mathrm{L}$ de DMSO e foi feita a leitura em Espectrofotômetro Infinite M200 TECAN a $540 \mathrm{~nm}$. Foram realizados pelo menos dois experimentos independentes com as concentrações quadruplicadas.

\subsection{Análise estatística}

Para as análises estatísticas, foi utilizado o software GraphPad Prism 5.0 (GraphPad Software, Inc. La Jolla, CA, USA) e todos os resultados foram expressos como média ( \pm desvio padrão). As determinações foram efetuadas em triplicata e os dados do efeito dos parâmetros de secagem (temperatura e concentração de dióxido de silício coloidal) foram submetidos à análise de variância ANOVA e as médias 
comparadas pelo teste de Tukey ao nível de significância de 5\%.

\section{RESULTADOS E DISCUSSÃO}

\subsection{Caracterização da solução extrativa (SEHP) obtida a partir da biomassa de Haematococcus pluvialis}

Muitos métodos de extração de carotenoides a partir de materiais biológicos têm sido testados, incluindo a extração por solventes, a extração em fase sólida e a extração por fluidos supercríticos. Dentre estes, a extração com o uso de solventes orgânicos é o que mais tem sido aplicado para extração de carotenoides totais, pois é um método simples e de baixo custo. Independente da técnica empregada, estudos têm mostrado que a extração de carotenoides é altamente afetada pelo tipo de solvente, relação solvente:biomassa, tempo e condições de armazenamento [26]. Neste trabalho o método clássico de extração de carotenoides descrito por MEZZONO et al. [21] foi utilizado para a preparação da SEHP. A caracterização foi realizada como etapa intermediária para a preparação dos extratos secos e os ensaios realizados foram limitados àqueles frequentemente utilizados em pesquisa tecnológica desta natureza, ou seja, determinação do resíduo seco, $\mathrm{pH}$, densidade, além do teor de carotenoides totais. Os resultados obtidos na caracterização da solução extrativa (SEHP) de H. pluvialis encontram-se relacionados na Tabela 2. A avaliação do resíduo seco da solução extrativa apresentou um teor de sólidos de 1,60\% $(\mathrm{m} / \mathrm{m})$, o que pode ser considerado baixo. O resíduo seco traduz-se no teor de sólidos dispersos na solução concentrada sendo útil na previsão do rendimento teórico do produto seco produzido. De modo geral, valores de sólidos em dispersão inferiores a $10 \%(\mathrm{~m} / \mathrm{v})$ podem comprometer o bom rendimento da operação de secagem em spray dryer, de forma a resultar em partículas de tamanho muito reduzido e desta maneira, atravessar os filtros do sistema de exaustão [27]. Ainda, o teor de resíduo sólido presente na amostra possibilita fazer o cálculo do percentual de adjuvantes a ser adicionado na solução extrativa para produção do extrato seco por spray dryier [28]. O sistema de ligações duplas conjugadas que constitui o cromóforo que fornece aos carotenoides a sua coloração e sua absorção no visível serve como base para sua identificação e quantificação [29]. É descrito na literatura que a fração de carotenoides da microalga Haematococcus pluvialis contém cerca de $70 \%$ de monoésteres e $10 \%$ de diésteres de astaxantina, e $5 \%$ de astaxantina livre, além de $\beta$-caroteno, cantaxantina e luteína. Vários métodos têm sido usados para a determinação destes carotenoides, incluindo métodos espectrofotométricos e de cromatografia líquida, sendo que os primeiros apresentam as vantagens de serem mais rápidos e de baixo custo, uma vez que o teor pode ser estimado sem requerer a separação e/ou tratamento prévio da amostra. Assim, neste estudo, o teor de carotenoides totais foi determinado de acordo com a Lei de Lambert-Beer e o valor encontrado foi de $82,1 \pm 2,1 \mu \mathrm{g} / \mathrm{mL}$ (Tabela 2). Considerando o volume de solução extrativa obtida $(800 \mathrm{~mL})$ e a massa de biomassa utilizada $(5 \mathrm{~g})$, a massa total extraída de carotenoides totais foi de $65,68 \mathrm{mg}$ ou $13,14 \mathrm{mg} / \mathrm{g}$ de biomassa. Este valor foi mais baixo que aqueles encontrados por PASSOS et al. [30], em um estudo que visava avaliar o feito do tipo de solvente extrator sobre o teor de carotenoides de H. pluvialis.

Tabela 2: Valores médios e desvio padrão $(\sigma)$ para o resíduo seco, $\mathrm{pH}$, densidade e teor de carotenoides totais obtidos na caracterização da solução extrativa (SEHP) de H. pluvialis $(\mathrm{n}=3)$.

\begin{tabular}{ll}
\hline PARÂMETROS ANALISADOS & DADOS EXPERIMENTAIS (MÉDIA $\pm \sigma$ ) \\
\hline Resíduo seco $(\% \mathrm{~m} / \mathrm{m})$ & $1,60 \pm 0,02$ \\
$\mathrm{pH}$ & $5,40 \pm 0,12$ \\
Densidade $(\mathrm{g} / \mathrm{mL})$ & $0,99 \pm 0,03$ \\
Teor de carotenoides totais $(\mu \mathrm{g} / \mathrm{mL})$ & $82,1 \pm 2,10$ \\
\hline
\end{tabular}

\subsection{Preparação dos extratos secos de Haematococcus pluvialis por secagem em torre de aspersão (spray-drying)}

A secagem é uma das operações mais frequentes na produção de medicamentos, sendo usada para obtenção de pós e grânulos, que podem ainda ser processados para gerar outras formas farmacêuticas sólidas, como as cápsulas e os comprimidos [14]. A remoção da água proporciona um aumento na estabilidade química, físico-química e microbiológica, aumentando assim a vida útil do produto final. A 
secagem em torre de aspersão tem sido empregada para a secagem de inúmeras soluções extrativas vegetais, pois é um processo rápido, facilmente escalonável, e permite a obtenção de pós secos com boas características físico-químicas e elevado rendimento [31]. Entretanto, o sucesso da operação de secagem depende das características físicas e químicas do material a ser seco e das condições de processamento. Em geral, materiais de partida ricos em açúcares e ácidos de baixo peso molecular conduzem à obtenção de pós muito higroscópicos, suscetíveis à aglomeração e com problemas de fluidez, que muitas vezes podem se aderir à torre de secagem, levando ao baixo rendimento da operação [32]. Estes problemas têm sido contornados pela adição de adjuvantes de secagem. Os mais comumente empregados são: amido, ciclodextrinas, dióxido de silício coloidal, fosfato tricálcico, gelatina, goma arábica, lactose, maltodextrinas, entre outros [14]. Neste trabalho, ensaios preliminares levaram à seleção do dióxido de silício coloidal como adjuvante de secagem.

\subsection{Avaliação dos parâmetros de secagem sobre as características químicas e físico-químicas dos extratos secos}

\subsubsection{Rendimento e teor de umidade}

Vários fatores afetam a secagem por spray-drying, incluindo as características do material a ser seco e os parâmetros do processo. Dentre eles, a concentração de sólidos presentes no líquido de alimentação exerce grande impacto sobre a eficiência da operação de secagem [33]. O teor de sólidos que permita a obtenção de um produto com características desejáveis deve ser otimizado, visto que este pode impactar no custo do processo. Em geral, a operação dever ser realizada com o máximo teor de sólidos possível, possibilitando uma utilização adequada do calor. Baixas concentrações de sólidos necessitam que grande quantidade de solvente seja eliminada e, portanto, requerem uma maior quantidade de calor para a secagem [31]. Em relação ao processo, um dos parâmetros mais importantes é a temperatura do ar de entrada, sendo determinante na qualidade do produto obtido. $\mathrm{O}$ aumento na temperatura do material de entrada facilita o processo de secagem, pois normalmente reduz a tensão superficial e a viscosidade, facilitando a formação de gotículas [14]. Assim, neste trabalho foi avaliado o efeito da concentração de dióxido de silício coloidal $(2 \%, 4 \%$ e $6 \%)$ e temperatura de entrada $\left(150^{\circ} \mathrm{C}\right.$ e $\left.175^{\circ} \mathrm{C}\right)$, sobre as características físico-químicas dos extratos secos. Os resultados obtidos na determinação do rendimento da operação e teor de umidade estão apresentados na Tabela 3.

Tabela 3: Valores médios e desvio padrão $(\sigma)$ obtidos do rendimento e de teor de umidade dos extratos secos (ES) em função das condições de secagem $(n=3)$.

\begin{tabular}{lllll}
\hline $\begin{array}{l}\text { EXTRATO } \\
\text { SECO }\end{array}$ & $\begin{array}{l}\text { AEROSIL } \\
\mathbf{2 0 0}(\%)\end{array}$ & $\begin{array}{l}\text { TEMPERATURA DE } \\
\text { ENTRADA }\left({ }^{\circ} \mathbf{C}\right)\end{array}$ & $\begin{array}{l}\text { RENDIMENTO } \\
(\%, \mathbf{M} \mathbf{\pm} \boldsymbol{)})\end{array}$ & $\begin{array}{l}\text { TEOR DE UMIDADE } \\
(\%, \mathbf{M} \pm \boldsymbol{\sigma})\end{array}$ \\
\hline ES1 & 2 & 150 & $87,8 \pm 0,01$ & $1,8 \pm 0,19$ \\
ES2 & 4 & 150 & $88,9 \pm 0,02$ & $1,6 \pm 0,04$ \\
ES3 & 6 & 150 & $88,0 \pm 0,06$ & $1,4 \pm 0,20$ \\
ES4 & 2 & 175 & $94,6 \pm 0,04$ & $1,4 \pm 0,20$ \\
ES5 & 4 & 175 & $93,3 \pm 0,30$ & $1,2 \pm 0,20$ \\
ES6 & 6 & 175 & $94,0 \pm 0,35$ & $1,0 \pm 0,13$ \\
\hline
\end{tabular}

${ }^{1}$ Calculado em relação ao volume de SEHP. Todas as médias obtidas no rendimento e o teor de umidade para as diferentes temperaturas de entrada e concentração de aerosil diferem estatisticamente entre si para $\mathrm{p}<0,05$.

Como é possível observar na Tabela 3, os valores de rendimento de secagem variaram entre 87,8 e $94,6 \%$, sendo que foram maiores quando a maior temperatura de secagem foi utilizada. A análise estatística evidenciou que o rendimento é afetado unicamente pela temperatura de entrada do spray-dryer $(\mathrm{P}<0,05)$, mas não pela concentração de Aerosil@. O teor de umidade variou entre 1,0 e $1,8 \%(\mathrm{~m} / \mathrm{m})$ e foi afetado por ambos os parâmetros de secagem avaliados. Os resultados observados neste trabalho são semelhantes aos encontrados por outros autores. A influência dos parâmetros de temperatura de entrada e concentração de dióxido de silício coloidal (Aerosil® 200) sobre as características de produtos secos por aspersão da Schinus terebinthifolius (aroeira vermelha) foi investigada por VASCONCELOS et al. [33].

No trabalho destes autores, os resultados revelaram que o rendimento do processo aumentou nos 
níveis mais altos de Aerosil@, na concentração de $30 \%$ obtiveram os menores valores para a umidade residual, independentemente da temperatura de entrada. Já a higroscopicidade e a umidade residual dos produtos foram inversamente proporcionais ao aumento da temperatura de entrada e à concentração do adjuvante. Similarmente, estudos mostraram que o teor de umidade do tomate em pó [34], pó de suco de laranja [35], suco de cacto de pera em pó [36] e cenoura preta em pó [37] diminuiu com o aumento da temperatura de secagem.

\subsubsection{Tamanho de partícula}

A distribuição de tamanho de partícula é uma das características mais importantes de um sistema de pó ou de partículas, pois afeta tanto as propriedades como o desempenho dos produtos intermediários e finais [38]. Certas propriedades químicas e físicas dos fármacos são afetadas pelo tamanho, forma e morfologia da superfície da partícula, assim como a homogeneidade da formulação, velocidade de dissolução e biodisponibilidade. Além disso, as propriedades de fluxo estão diretamente relacionadas ao tamanho de partícula [31] [39]. Na Tabela 4 estão apresentados os valores de tamanho de partículas e a distribuição granulométrica, assim como o diâmetro médio $\left(\mathrm{d}_{4,3}\right)$ e de Span de todas as formulações e determinada por difratometria a laser. $\mathrm{O}$ diâmetro médio das partículas $\left(\mathrm{d}_{4,3}\right)$ variou entre 13,41 e 14,84 $\mu \mathrm{m}$ e os valores de Span foram baixos, variando entre 1,25 e 1,54 (Tabela 4). Os valores de Span, que fornecem um indicativo da amplitude da distribuição granulométrica, indicaram uma estreita distribuição de tamanho, uma vez que quanto menores eles são, mais estreita é a distribuição [40]. Este resultado pode estar relacionado com a baixa viscosidade das misturas de adjuvante e solução extrativa. Como o mesmo adjuvante de secagem foi utilizado para todas as formulações, provavelmente as diferentes concentrações utilizadas não foram capazes de modificar as características do líquido de alimentação e, portanto, do perfil da distribuição de tamanho de partícula.

Tabela 4: Valores médios e desvio padrão $(\sigma)$ do tamanho de partícula e distribuição granulométrica obtidos a partir dos extratos secos (ES) de H. pluvialis (n=3).

\begin{tabular}{llllll}
\hline EXTRATO & $\mathbf{d}_{10 \%} \pm \sigma(\boldsymbol{\mu m})$ & $\mathbf{d}_{50 \%} \pm \sigma(\boldsymbol{\mu m})$ & $\mathbf{d}_{90 \%} \pm \sigma(\boldsymbol{\mu m})$ & $\mathbf{d}_{4,3} \pm \sigma(\boldsymbol{\mu m})$ & Span $\pm \sigma$ \\
\hline ES1 & $6,65 \pm 0,11$ & $12,50 \pm 0,01$ & $22,89 \pm 0,39$ & $13,78 \pm 0,07$ & $1,29 \pm 0,04$ \\
ES2 & $6,44 \pm 0,15$ & $11,86 \pm 0,47$ & $22,77 \pm 0,76$ & $13,62 \pm 0,19$ & $1,35 \pm 0,06$ \\
ES3 & $6,49 \pm 0,15$ & $11,86 \pm 0,56$ & $22,28 \pm 0,89$ & $13,41 \pm 0,27$ & $1,32 \pm 0,06$ \\
ES4 & $6,41 \pm 0,10$ & $12,29 \pm 0,86$ & $23,82 \pm 0,80$ & $14,35 \pm 0,27$ & $1,45 \pm 0,07$ \\
ES5 & $6,01 \pm 0,03$ & $11,06 \pm 0,10$ & $22,73 \pm 0,34$ & $14,08 \pm 0,15$ & $1,25 \pm 0,03$ \\
ES6 & $6,36 \pm 0,01$ & $12,93 \pm 0,06$ & $23,38 \pm 0,61$ & $14,84 \pm 1,33$ & $1,54 \pm 0,03$ \\
\hline
\end{tabular}

Na tabela: $d_{10 \%}, d_{50 \%}$ e $d_{90 \%}$ referem-se ao diâmetro da partícula correspondente a $10 \%, 50 \%$ e $90 \%$ da distribuição acumulada e $\mathrm{d}_{4,3}$ corresponde ao diâmetro médio equivalente a uma esfera de igual volume. Todas as médias obtidas no tamanho de partícula $\left(\mathrm{d}_{50 \%}\right.$ e $\left.\mathrm{d}_{50 \%}\right)$ diferem estatisticamente entre si para $\mathrm{p}<$ 0,05 .

\subsubsection{Avaliação da morfologia}

As fotomicrografias dos extratos secos de H. pluvialis são mostradas no painel da Figura 1. A análise por microscopia eletrônica de varredura demonstra que os extratos secos de H. pluvialis apresentaram formato esférico e superfície lisa, característico dos pós produzidos pelo processo de secagem por aspersão, sem a presença de poros superficiais. As partículas exibiram tamanhos de alguns micrometros, estando de acordo com os resultados obtidos pela técnica de difração a laser. NIJDAM et al. [41] observaram a formação de partículas mais rígidas com a utilização de temperaturas mais elevadas, na produção de partículas de leite em pó por spray-drying. De acordo com estes autores, quando a temperatura é suficientemente alta, a umidade evapora rapidamente e a superfície se torna seca e dura, de modo que as partículas não murcham. No entanto, quando a temperatura de secagem é mais baixa, a superfície das partículas permanece úmida e flexível por mais tempo e, dessa forma, as partículas podem ficar murchas e enrugadas, quando resfriadas. Em nosso trabalho, observamos partículas esféricas e lisas, sugerindo que as temperaturas testadas foram adequadas e suficientes para permitir a evaporação da umidade dos extratos. Outro fator importante a ser considerado, é a viscosidade do líquido de alimentação, que está relacionado com a concentração de sólidos, pois esta interfere na formação de gotas esféricas. De modo geral, menos energia ou menor pressão são aplicadas quando a viscosidade é mais baixa [42]. Neste estudo, não foram observadas diferenças na morfologia das partículas quando as 
diferentes condições de secagem foram testadas, sugerindo que as variações na temperatura de entrada ou a concentração de dióxido de silício coloidal testadas não induziram alterações nas características do líquido de alimentação e/ou no processo de secagem.

(a)

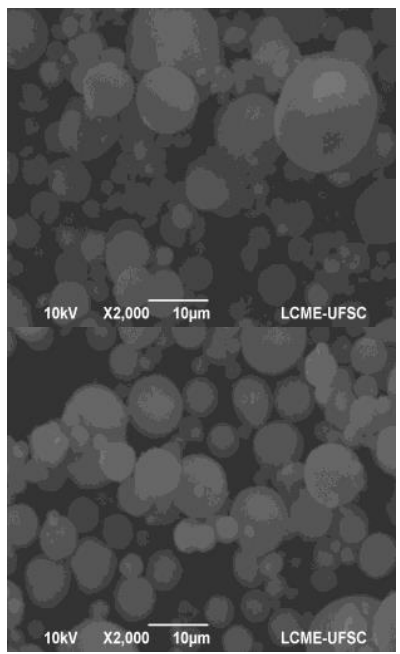

(b)

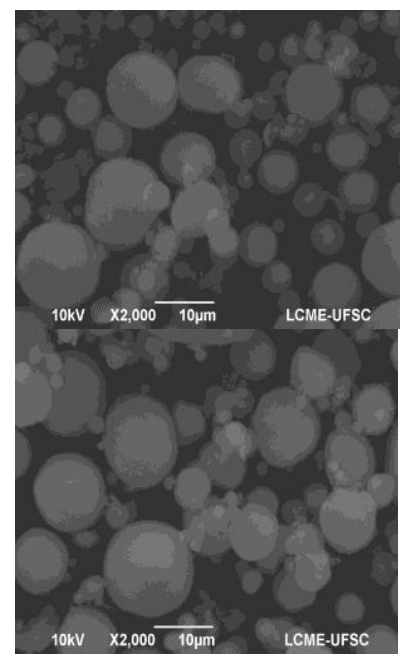

(c)

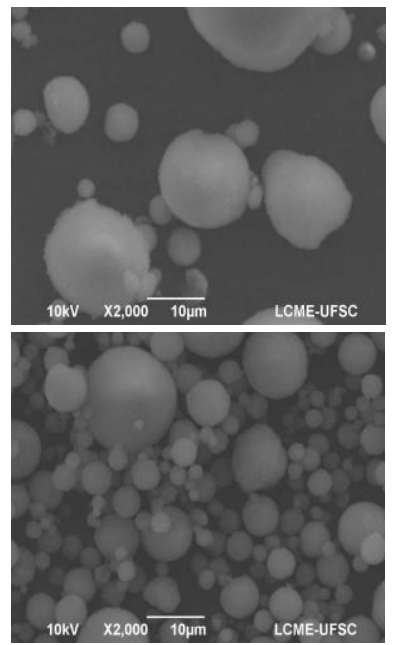

Figura 1: Fotomicrografias obtidas por microscopia eletrônica de varredura dos extratos secos da microalga Haematococcus pluvialis, preparados usando temperatura de entrada e dióxido de silício coloidal, respectivamente (a) $150{ }^{\circ} \mathrm{C}$ e $2 \%$, (b) $175{ }^{\circ} \mathrm{C}$ e $2 \%$, (c) $150{ }^{\circ} \mathrm{C}$ e $4 \%$, (d) $175{ }^{\circ} \mathrm{C}$ e $4 \%$, (e) $150{ }^{\circ} \mathrm{C}$ e $6 \%$ e (f) $175{ }^{\circ} \mathrm{C}$ e $6 \%$.

\subsubsection{Determinação da densidade aparente e de compactação}

$\mathrm{Na}$ secagem em torre de aspersão, a influência do teor de sólidos no material de partida também é refletida na densidade do produto final [16]. De acordo com CAO et al [43], o aumento no conteúdo de sólidos, eleva a viscosidade, resultando em pós mais densos. Por outro lado, quanto menor o conteúdo de sólidos em uma suspensão, maior o espaço oco interno da partícula, com formação de partículas com paredes menos espessas e menos densas [14]. A densidade de um pó está diretamente ligada à estrutura das partículas e, consequentemente, à capacidade de fluxo e compressão. Representa um parâmetro importante na etapa de desenvolvimento de uma formulação, porém, não há uma escala para determinação dos limites [44]. Os valores de densidade aparente e compactada dos extratos secos (Tabela 5) foram em torno de 0,11 e $0,12 \mathrm{~g} / \mathrm{mL}$, respectivamente, e não parecem ter sido afetados pelas condições de secagem testadas.

Tabela 5: Valores médios e desvio padrão $(\sigma)$ obtidos dos valores da densidade aparente e de compactação dos extratos secos (ES) de H. pluvialis ( $\mathrm{n}=3$ ).

\begin{tabular}{lll}
\hline EXTRATO & $\begin{array}{l}\text { DENSIDADE } \\
\text { APARENTE } \\
(\mathbf{g} / \mathbf{m L}, \mathbf{M} \pm \boldsymbol{\sigma})\end{array}$ & $\begin{array}{l}\text { DENSIDADE } \\
\text { COMPACTADA } \\
(\mathbf{g} / \mathbf{m L}, \mathbf{M} \pm \boldsymbol{\sigma})\end{array}$ \\
\hline ES1 & $0,110 \pm 0,002$ & $0,132 \pm 0,001$ \\
ES2 & $0,107 \pm 0,002$ & $0,125 \pm 0,002$ \\
ES3 & $0,104 \pm 0,003$ & $0,124 \pm 0,003$ \\
ES4 & $0,113 \pm 0,004$ & $0,125 \pm 0,004$ \\
ES5 & $0,125 \pm 0,004$ & $0,139 \pm 0,001$ \\
ES6 & $0,113 \pm 0,003$ & $0,126 \pm 0,003$ \\
\hline
\end{tabular}

\subsubsection{Teor de carotenoides totais nos extratos secos}

Os carotenoides são substâncias bastante instáveis e muito sensíveis ao oxigênio, luz e calor. Apesar da secagem por spray-drying utilizar o calor, o curto período de exposição dos extratos ao aquecimento parece ser vantajosa. As temperaturas utilizadas para a produção dos extratos secos foram de $150{ }^{\circ} \mathrm{C}$ e 175 ${ }^{\circ} \mathrm{C}$, com valores de teor de carotenoides totais que variaram de acordo com as diferentes condições de secagem (Tabela 6). A análise estatística evidenciou que tanto a temperatura como a concentração de Aerosil afetaram significativamente o teor de carotenoides totais nos extratos secos $(\mathrm{P}>0.05)$. $\mathrm{O}$ extrato ES1 apresentou maior concentração de carotenoides totais, além da maior recuperação do teor em relação à solução extrativa. $\mathrm{O}$ aumento da temperatura e o aumento na concentração do adjuvante de secagem 
levaram à redução significativa do teor de carotenoides totais. A decomposição térmica e oxidação foram possivelmente os responsáveis por esta diminuição. RYCKEBOSCH et al. [19] relataram que a microalga Phaeodactylum tricornutum seca por spray-drying foi a mais suscetível à degradação do que aquelas secas por liofilização (freeze-drying). Por outro lado, apesar das altas temperaturas utilizadas no processo de secagem por spray-drying, LEACH et al. [17] relataram uma elevada recuperação de carotenoides após secagem da Dunaliella salina. Segundo os autores, a geração de um jato de pulverização atomizado proporciona uma grande área de superfície para rápida evaporação de água. Consequentemente, a temperatura média das gotas é suficientemente baixa, e o tempo de permanência na câmara de secagem das partículas secas é curto o suficiente para que a oxidação excessiva dos carotenoides seja evitada. De acordo com GOULA E ADAMOPOULOS [34], o aumento da temperatura de entrada do spray dryer resultou em maior perda no teor de licopeno no tomate em pó. Similarmente, QUEK et al. [46] observaram uma diminuição do teor de licopeno e $\beta$-caroteno na secagem em atomização da melancia com o aumento da temperatura do ar de entrada.

Tabela 6: Valores médios e desvio padrão $(\sigma)$ do teor de carotenoides totais nos extratos secos (ES) de H. pluvialis.

\begin{tabular}{ccc}
\hline EXTRATO SECO & $\begin{array}{c}\text { TEOR DE CAROTENOIDES TOTAIS } \\
(\mathbf{g} / \mathbf{1 0 0} \mathbf{g} \mathbf{M} \pm \boldsymbol{\sigma})\end{array}$ & $\begin{array}{c}\text { RECUPERAÇÃO } \\
(\%, \mathbf{M} \pm \boldsymbol{\sigma})\end{array}$ \\
\hline ES1 & $2,27 \pm 0,006$ & $99,87 \pm 0,009$ \\
ES2 & $1,43 \pm 0,007$ & $98,26 \pm 0,001$ \\
ES3 & $0,79 \pm 0,003$ & $73,70 \pm 0,001$ \\
ES4 & $2,13 \pm 0,066$ & $92,92 \pm 0,009$ \\
ES5 & $1,15 \pm 0,008$ & $79,11 \pm 0,001$ \\
ES6 & $0,73 \pm 0,006$ & $67,87 \pm 0,002$ \\
\hline
\end{tabular}

$\mathrm{F}_{\text {cal }}$ temperatura $=5,15 ; \mathrm{F}_{\text {cal }}$ concentração aerosil $=175,04 ; \mathrm{F}_{\text {crit }}=3,11$. Todas as médias obtidas teor de carotenoides para as diferentes temperaturas de entrada e concentração de aerosil diferem estatisticamente entre si para $\mathrm{p}<0,05$

\subsubsection{Avaliação do perfil de dissolução de carotenoides totais a partir dos extratos secos de Haematococcus pluvialis}

No desenvolvimento de formas farmacêuticas, estudos de dissolução são particularmente importantes, pois permitem, por meio do perfil in vitro, sugerir o comportamento da liberação do fármaco in vivo. De forma simplificada, a dissolução pode ser entendida como a liberação de um fármaco da sua forma farmacêutica, tornando-se disponível para absorção pelo organismo [45]. Desta forma, o ensaio de dissolução corresponde a um teste físico, no qual o fármaco passa para a forma solúvel a partir da forma farmacêutica sólida intacta ou dos fragmentos formados durante o ensaio [47]. Em ensaios de dissolução, as condições sink devem sempre ser respeitadas. Como via de regra admite-se que condições sink são atingidas quando a concentração máxima do fármaco no meio de dissolução corresponde a $10 \%$ da sua concentração na saturação [48]. Assim, vários meios de dissolução foram previamente testados por meio da adição de quantidades crescentes dos extratos e avaliação visual da solubilização. A partir destes dados, a solução de lauril sulfato de sódio $0,5 \%(\mathrm{~m} / \mathrm{V})$ foi selecionada como meio de dissolução. As concentrações de carotenoides totais foram calculadas conforme descrito anteriormente. A partir dos resultados, curvas de percentual de carotenoides totais liberado (\%) versus tempo (min) foram construídas. A partir dos perfis de dissolução, os valores de t50\% (tempo para dissolução de $50 \%$ de carotenoides totais) e eficiência de dissolução (ED\%) foram estimados. Os valores de dissolução de carotenoides totais após 60 minutos variaram entre 82,6 e 89,2\% para todas as amostras testadas (Figura 2). O valor de desvio padrão relativo foi $2,72 \%$, portanto, inferior a $5 \%$, o que certifica a precisão do método, conforme preconizado pela ANVISA [22]. O uso da sílica coloidal pode minimizar a geração da carga eletrostática entre os pós com a parede do spray dryer, levando a um aumento da produtividade bem como na melhoria das propriedades de fluxo dos pós. Além disso, a sílica também funciona como adsorvente (proporciona elevada área superficial), desempenhando um papel importante no aumento da solubilidade [49]. Inúmeros trabalhos de pesquisa também têm sido relatados sobre melhoria na dissolução, rendimento do processo e estabilidade dos extratos após a adição do Aerosil@ na solução a ser seca em spray dryer [50] [51] [52]. 
(a)

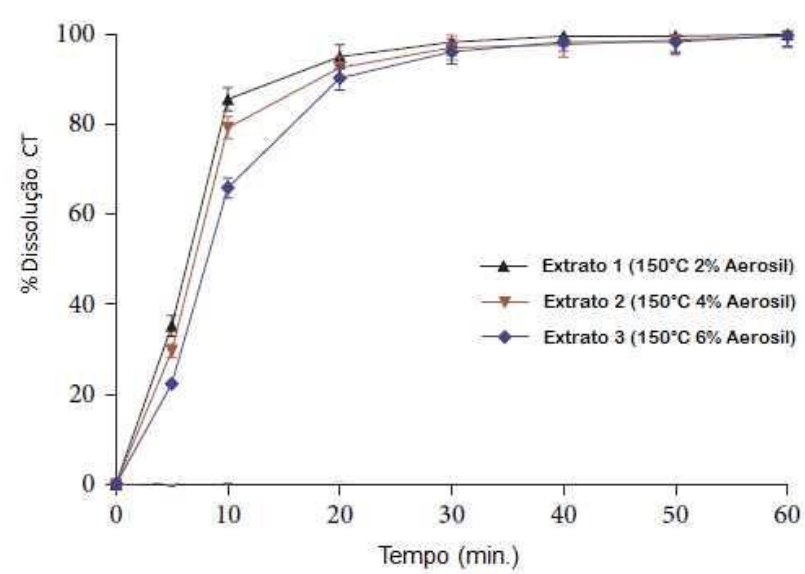

(b)

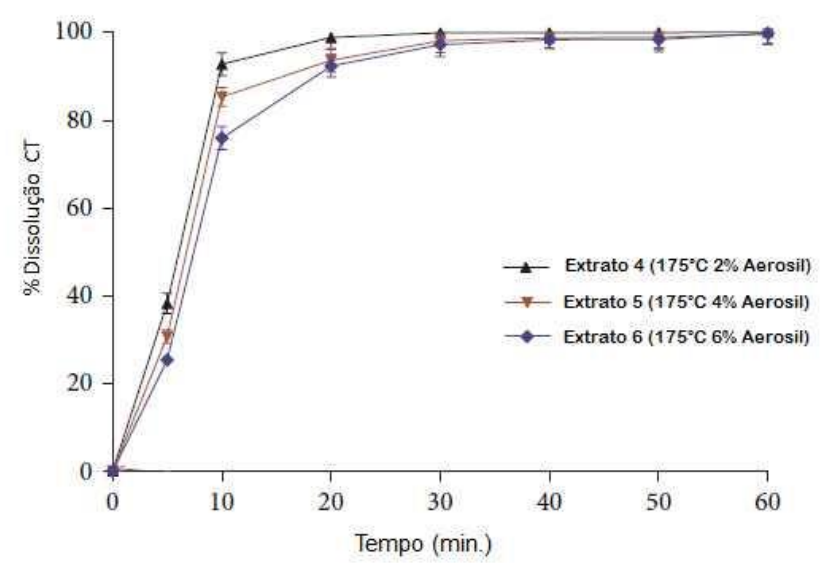

Figura 2: Perfis de dissolução de carotenoides totais (\% de dissolução de CT) a partir dos extratos secos de $H$. pluvialis obtidos usando as temperaturas de entradas de (a) $150{ }^{\circ} \mathrm{C}$ e (b) $175{ }^{\circ} \mathrm{C}$. Todas as médias obtidas no ensaio de dissolução após 60 minutos para as diferentes temperaturas de entrada e concentração de aerosil diferem estatisticamente entre si para $\mathrm{p}<0,05$.

\subsubsection{Avaliação da atividade antioxidante da biomassa, solução extrativa e dos extratos secos de Haematococcus pluvialis}

Os carotenoides são particularmente vulneráveis a processos de tratamento térmico e de degradação oxidativa devido a sua estrutura única, que contém um sistema de ligação dupla conjugada ao longo de todo o comprimento da cadeia de polieno [38]. Neste sentido, foi avaliada a atividade oxidante dos extratos obtidos após a secagem por spray drying pelo método do DPPH. Este método é baseado na captura do radical livre estável 1,1 difenil-2-picrilhidrazil por substâncias capazes de doar prótons, levando à formação de sua forma reduzida [53] e amplamente utilizado para a medição da capacidade de alimentos e produtos fitofarmacêuticos em sequestrar radicais livres. À medida que o DPPH sofre redução, observa-se a mudança da coloração da solução original de violeta intensa para amarela, proporcional à concentração da substância antioxidante em questão. Os valores obtidos para a avaliação da atividade antioxidante das amostras (biomassa, SEHP e extratos secos) variaram entre 55,78 e 77,83\%, sendo que os menores valores encontrados foram obtidos para os extratos secos preparados com temperatura de entrada de $175^{\circ} \mathrm{C}$ (Tabela 7). A provável explicação para isso é que o tratamento térmico levou a destruição da estrutura dos carotenoides com o processo de secagem, levando a uma redução da atividade antioxidante, sugerindo que a principal influência na diminuição da atividade antioxidante parece ser a elevação da temperatura na produção dos extratos secos. De acordo com KATSUBE et al. [54], a atividade antioxidante dos extratos de folhas de amoreira foi significativamente reduzida, quando temperaturas de secagem de ar acima de $70^{\circ} \mathrm{C}$ foram utilizadas. Resultados semelhantes também foram descritos por MRKIC et al .[55] avaliando os efeitos dos parâmetros de secagem sobre os compostos antioxidantes do brócolis (Brassica oleracea L.). 
Tabela 7: Valores médios e desvio padrão $(\sigma)$ do percentual de atividade antioxidante da biomassa de H. pluvialis, da solução extrativa (SEHP) e dos extratos secos (ES) de H. pluvialis.

\begin{tabular}{ll}
\hline $\begin{array}{l}\text { AMOSTRA } \\
\text { (dispersão } \mathbf{1 0} \mathbf{~} \mathbf{g} / \mathbf{m L})\end{array}$ & $\begin{array}{l}\text { ATIVIDADE ANTIOXIDANTE } \\
(\%, \mathbf{M} \pm \boldsymbol{\sigma} \text { ) }\end{array}$ \\
\hline Biomassa & $77,83 \pm 0,16$ \\
SEHP & $71,38 \pm 0,25$ \\
ES1 & $65,93 \pm 0,05$ \\
ES2 & $65,75 \pm 0,08$ \\
ES3 & $60,98 \pm 0,06$ \\
ES4 & $56,05 \pm 0,03$ \\
ES5 & $57,15 \pm 0,03$ \\
ES6 & $55,78 \pm 0,06$ \\
\hline
\end{tabular}

Todas as médias obtidas na avaliação da atividade antioxidante para as diferentes temperaturas de entrada e concentração de aerosil diferem estatisticamente entre si para $\mathrm{p}<0,05$.

\subsubsection{Avaliação da atividade citotóxica do extrato dos carotenoides obtido a partir dos extratos secos}

O papel dos carotenoides na prevenção e redução da incidência de câncer tem recebido cada vez mais atenção devido ao aumento das evidências dos estudos epidemiológicos, dos trabalhos realizados em cultura celular, de estudos em animais e ainda, de testes clínicos [56] [57] [1] [6]. Para avaliar o efeito dos carotenoides obtidos a partir dos extratos secos sobre a viabilidade celular foi utilizado o teste do MTT, que mede a atividade da desidrogenase mitocondrial, através da redução do brometo de 3-(4,5dimetiltiazol-2-il)-2,5-difenil tetrazolio em formazan, nas células viáveis [25]. A Figura 3 demonstra os resultados obtidos para a viabilidade celular após a incubação de soluções crescentes de carotenoides obtidas a partir dos extratos secos (ES1), em células de melanoma murino B16F10, em períodos de tempo de 72 e 96 horas. Como pode ser observada, a adição da solução de carotenoides, obtida a partir dos extratos secos de $H$. pluvialis, provocou uma inibição no crescimento celular em todas as concentrações testadas quando comparada ao controle (Figura 3). Esta inibição foi dose e tempo dependente. A concentração inibitória máxima da solução de carotenoides foi obtida na maior concentração testada (5 $\mu \mathrm{M})$, com inibições de 66,58 e 82,91\% da viabilidade celular, para os tempos de incubação de 72 e 96 horas, respectivamente (Figura 3). Os valores de $\mathrm{CI}_{50}$, obtidos da curva de concentração-resposta, foram 3,58 e 3,27 $\mu \mathrm{M}$ nos intervalos de tempo de 72 e $96 \mathrm{~h}$, respectivamente. Os resultados demonstrados na avaliação da citotoxicidade sugerem a eficácia desse extrato em reduzir a viabilidade celular na linhagem tumoral testada, avaliada como a porcentagem de redução da viabilidade dependente da concentração testada. Estes resultados corroboram os outros trabalhos publicados, avaliando o efeito de constituintes carotenoides sobre a viabilidade celular. No estudo realizado por ZHANG et al. [58], a alta proporção de células de leucemia humana (K562) na fase G0/G1 e a apoptose, resultaram na redução da proliferação e viabilidade celular induzidas pelos carotenoides testados ( $\beta$-caroteno, astaxantina capsantina e bixina). CUI et al.[59], também demonstraram que o $\beta$-caroteno foi capaz de inibir a viabilidade de células MCF7 (células de carcinoma de mama humano) de maneira tempo e concentração dependente. Estes autores verificaram que na concentração de $50 \mathrm{uM}$ de $\beta$-caroteno, a viabilidade celular foi reduzida para $42 \%$ quando o tempo de tratamento de $96 \mathrm{~h}$ de incubação foi testado. 


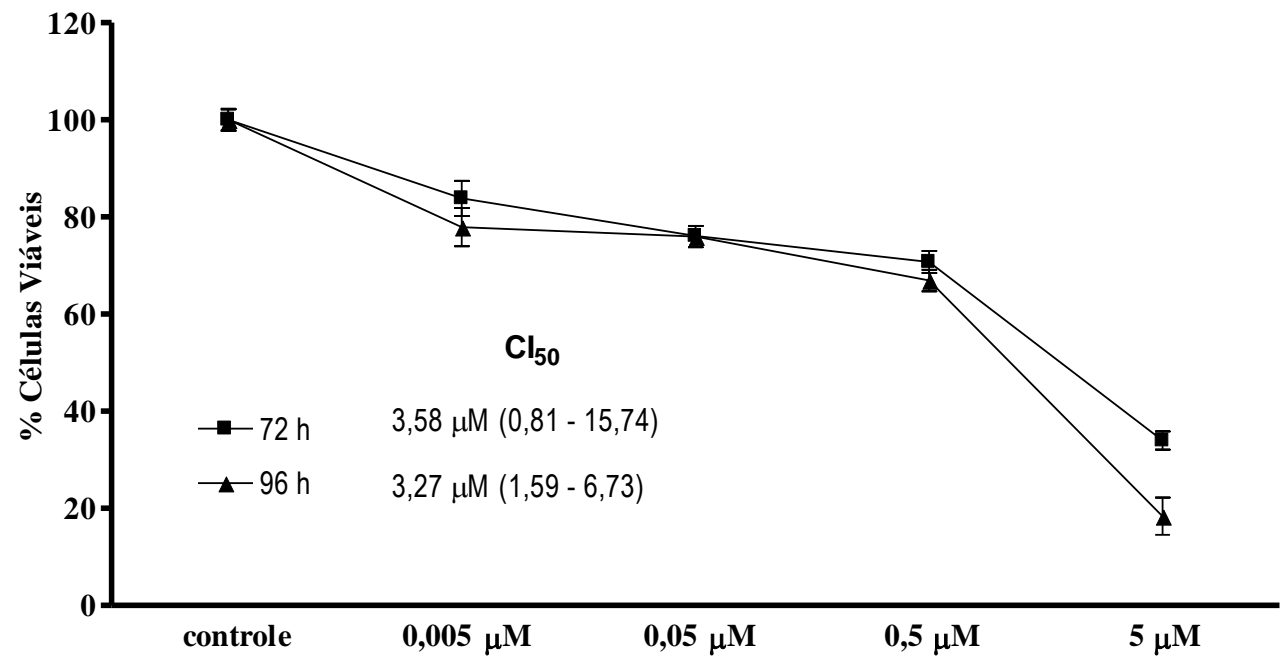

Figura 3: Efeito da solução de carotenoides (DMSO + DMEM) obtida a partir do extrato seco (ES1) de H. pluvialis sobre a viabilidade celular. O percentual de células viáveis, considerando o controle como 100\% (tratadas apenas com o veículo), foi obtido através da densidade óptica decorrente da oxidação metabólica do MTT. Cada ponto representa a média \pm Erro Padrão da Média de pelo menos dois experimentos independentes com as concentrações quadruplicadas. Todas as médias obtidas nas diferentes concentrações testadas diferem estatisticamente em relação ao controle para $\mathrm{p}<0,05$.

\section{CONCLUSÃO}

Neste trabalho, a extração de carotenoides a partir da biomassa da $H$. Pluvialis, mostrou-se adequada com altos valores de rendimento. Observou-se que o aumento da temperatura e concentração do adjuvante de secagem proporcionou redução significativa do teor de carotenoides totais, também verificado por outros autores e provavelmente relacionada com o processo de secagem. A atividade oxidante dos extratos obtidos após a secagem por spray-drying pelo método do DPPH foi reduzida, estando relacionada a exposição ao calor utilizado para a secagem. A atividade antiproliferativa dos extratos de carotenoides foi avaliada e as maiores concentrações testadas reduziram a viabilidade de células de melanoma murino B16F10, em 66,58 e 82,91\%, em períodos de tempo de 72 e $96 \mathrm{~h}$. Assim, o conjunto de resultados demonstrou que a obtenção de extratos secos a partir da biomassa de Haematococcus pluvialis pela técnica de secagem em torre de aspersão (spray dryer) é uma técnica adequada para posterior manipulação destes extratos visando a produção de medicamentos.

\section{AGRADECIMENTOS}

Os autores agradecem a Universidade Federal de Santa Catarina (UFSC-Brasil), ao Conselho Nacional de Desenvolvimento Científico e Tecnológico (CNPq-Brasil) e à CAPES pelo apoio financeiro e bolsa de estudo. Agradecem também ao Prof. Dr. J. Assreuy pela disponibilidade do laboratório para os testes in vitro.

\section{BIBLIOGRAFIA}

[1] AGHAJANPOUR, M., NAZER, M.R., OBEIDAVI, Z., et al., "Functional foods and their role in cancer prevention and health promotion: a comprehensive review", American Journal of Cancer Research, v. 7, n. 4, pp. 740-769, Apr. 2017.

[2] AHMADINEJAD, F., GEIR MØLLER, S., HASHEMZADEH-CHALESHTORI, M., et al., "Molecular mechanisms behind free radical scavengers function against oxidative stress", Antioxidants (Basel), v. 10, n. 6, pp.51-65, Jul. 2017.

[3] KANG, H., KIM, H. "Astaxanthin and $\beta$-carotene in Helicobacter pylori-induced gastric inflammation: a mini-review on action mechanisms", Journal of Cancer Prevention, v. 22, n. 2, pp. $57-$ 61, Jun. 2017 
[4] OKADA, Y., ISHIKURA, M., MAOKA, T. "Bioavailability of astaxanthin in Haematococcus algal extract: the effects of timing of diet and smoking habits", Bioscience, Biotechnology, and Biochemistry, v.73, n.9, pp.1928-1932, Sep. 2009.

[5] MANABE, E., HANDA, O., NAITO, Y., et al., "Astaxanthin protects mesangial cells from hyperglycemia-induced oxidative signaling”, Journal of Cellular Biochemistry, v.103, n.6, pp.1925-1937, Apr. 2008.

[6] ZHANG, J., SUN, Z., SUN, P., et al., "Microalgal carotenoids: beneficial effects and potential in human health", Food \& Function, v.5, n.3, pp.413-425, Mar. 2014.

[7] LEE, S.J., BAI, S.K., LEE, K.S., et al., "Astaxanthin inhibits nitric oxide production and inflammatory gene expression by suppressing I (kappa) B kinase-dependent NF-kappa B activation", Molecules and Cells, v.31, n.1, pp.97-105, Aug. 2003.

[8] YASUI, Y., HOSOKAWA, M., MIKAMI, N., et al., "Dietary astaxanthin inhibits colitis and colitisassociated colon carcinogenesis in mice via modulation of the inflammatory cytokines", ChemicoBiological Interactions, v.193, n.1, pp.79-87, Aug. 2011.

[9] HUSSEIN, G., SANKAWA, U., GOTO, H., et al., “Astaxanthin, a carotenoid with potential in human health and nutrition", Journal of Natural Products, v.69, pp.443-449, Mar. 2006.

[10] KISHIMOTO, Y., YOSHIDA, H., KONDO K. "Potential Anti-Atherosclerotic Properties of Astaxanthin", Marine Drugs, v.14, n.2, pp.35-48, Feb. 2016.

[11] TOMINAGA, K., HONGO, N., KARATO, M., et al., "Cosmetic benefits of astaxanthin on humans subjects”, Acta Biochimica Polonica, v. 59, n. 1, pp.43-47, Mar. 2012.

[12] YOSHIHISA, Y., REHMAN, M.U., SHIMIZU, T. “Astaxanthin, a xanthophyll carotenoid, inhibits ultraviolet-induced apoptosis in keratinocytes”, Experimental Dermatology, v.23, n.3, pp.178-183, Mar. 2014.

[13] TEIXEIRA, H.F., BASSANI, V.L. "Avaliação da influência de adjuvantes farmacêuticos sobre características físicas, químicas, tecnológicas e farmacológicas de extratos secos nebulizados de Achyrocline satureioides (Lam.) DC.- Compositae - Marcela", Caderno de Farmácia (UFRGS), v.13, n.2, pp. 151-152, Jul. 1997.

[14] OLIVEIRA, O.W., PETROVICK, P.R. "Secagem por aspersão (spray drying) de extratos vegetais: bases e aplicações”, Brazilian Journal of Pharmacognosy, v.20, n.4, pp.641-650, Ago/Set. 2010.

[15] ZHU, F. "Encapsulation and delivery of food ingredients using starch based systems", Food Chemistry, v.15, n.229, pp.542-552, Aug. 2017.

[16] RATTI, C. "Hot air and freeze-drying of high-value foods: a review", Journal of Food Engineering, v. 49, n.4, pp.311-319, Sep. 2001.

[17] LEACH, G., OLIVEIRA, G., MORAIS, R. "Spray-drying of Dunaliella salina to produce a $\beta$ carotene rich powder", Journal of Industrial Microbiology and Biotechnology, v.20, n.2, pp. 82-85, Feb. 1998.

[18] CERÓN-GARCÍA , C., CAMPOS-PÉREZ, I., MACÍAS-SÁNCHEZ, MD., et al., "Stability of carotenoids in Scenedesmus almeriensis biomass and extracts under various storage conditions", Journal of Agricultural and Food Chemistry, v.9, n.11, pp.6944-6950, Jun. 2010.

[19] RYCKEBOSCH, E., MUYLAERT, K., EECKHOUT, M., et al., "Influence of drying and storage on lipid and carotenoid stability of the microalga Phaeodactylum tricornutum", Journal of Agricultural and Food Chemistry, v.26, n.20, pp.11063-11069, Oct. 2011.

[20] RAPOSO, M.F., MORAIS, A.M., MORAIS, R.M. "Effects of spray-drying and storage on astaxanthin content of Haematococcus pluvialis biomass", World Journal of Microbiology and Biotechnology, v.28, n.3, pp.1253-1257, Mar. 2012.

[21] MEZZOMO, N., MAESTRI, B., SANTOS, R.L., et al., "Pink shrimp ( $P$. brasiliensis and $P$. paulensis) residue: influence of extraction method on carotenoid concentration", Talanta, v.15, n.3, pp.1383-1391, Sep. 2011.

[22] DAVIES, B.H. "Carotenoids”, In: GOODWIN, T.W. (Ed.). 2. Chemistry and biochemistry of plant pigments. London, Academic, 1976. p.38-65. 
[23] BRASIL, Agência Nacional de Vigilância Sanitária (ANVISA), Resolução RE no 899, de 29 de maio de 2003, Determina a publicação do "Guia para validação de métodos analíticos e bioanalíticos" anexo, Diário Oficial da União, 02/06/2003.

[24] CHEN, J., SHI, J., MACNAUGHTON, L., et al., "The scavenging capacity of combinations of lycopene, $\beta$-carotene, vitamin $\mathrm{E}$, and vitamin $\mathrm{C}$ on the free radical 1,1-difenil-2-picrilhidrazil (DPPH)", Journal of Food Biochemistry, v. 33, n.2, pp. 232-245, Apr. 2009.

[25] MOSMANN, T. "Rapid colorimetric assay for cellular growth and survival: application to proliferation and cytotoxicity assays", Journal of Immunological Methods, v.16, n.65, pp. 55-63, Dec. 1983.

[26] WANG, L., LIU Y. "Optimization of solvent extraction conditions for total carotenoids in rapeseed using response surface methodology”, Natural Science, v.1, pp.23-29, 2009.

[27] LEMOS-SENNA, E.M.T., PETROVICK, P.R., GONZÁLES-ORTEGA, G., et al., "Preparation and characterization of spray dryer powders from Achyrocline satureiodes (Lam) DC extracts", Phytotherapy Research, v.11, pp. 133-127, 1997.

[28] ARARUNA, S.M. "Desenvolvimento e padronização (HPLC-DAD) do extrato seco por spray dryer de Amburana cearensis A.C. Smith (Cumaru)", Dissertação, PPGCF/UFC, Fortaleza,CE, Brasil, 2008.

[29] RODRIGUEZ-AMAYA, D.B., KIMURA, M., GODOY, H.T., et al., "Updated Brazilian database on food carotenoids: Factors affecting carotenoid composition", Journal of Food Composition and.Analysis, v.21, pp.445-463, 2008.

[30] PASSOS, R., MORIEL, D.G., LAGREZE, F., et al., "Fontes naturais de carotenoides de interesse para a aqüicultura: análise comparativa da eficiência de métodos de extração", Revista Brasileira de Engenharia da Pesca, v.2, n.1, pp.103-113, jan. 2007.

[31] MASTERS, K. Spray Drying Handbook, 4 ed., New York, John Miley, 1985.

[32] BHANDARI, B. R., DATTA, N., HOWES, T. "Problems associated with spray drying of sugar-rich foods", Drying Technology, v. 15, n. 2, pp. 671-684, 1997.

[33] VASCONCELOS, E.A.F., MEDEIROS, M.G.F., RAFFIN, F.N., et al., "Influência da temperatura de secagem e da concentração de Aerosil® 200 nas características dos extratos secos por aspersão da Schinus terebinthifolius Raddi (Anacardiaceae)", Revista Brasileira de Farmacognosia, v.15, pp.243249, 2005.

[34] GOULA, A.M., ADAMOPOULOS, K.G. "Stability of lycopene during spray drying of tomato pulp", Food Science and Technology, v.38, n.5, pp.479-487, 2005.

[35] CHEGINI, G. R., GHOBADIAN, B. "Effect of spray-drying conditions on physical properties of orange juice powder”, Drying Technology, v.23, n.3, pp.657-668, 2005.

[36] RODRÍGUEZ-HERNÁNDEZ, G.R., GONZÁLEZ-GARCÍA, R., GRAJALES-LAGUNES, A., et al., "Spray-drying of cactus pear juice (Opuntia streptacantha): effect on the physicochemical properties of powder and reconstituted product", Drying Technology, v.23, n.4, pp. 955-973, 2005.

[37] ERSUS, S., YURDAGEL, U. "Microencapsulation of anthocyanin pigments of black carrot (Daucus carota L.) by spray dryer”, Journal of Food Engineering, v.80, n.3, pp.805- 812, 2007.

[38] BRITTON, G. "Structure and properties of carotenoids in relation to function", The FASEB Journal, v.9, n.15, pp.1551-1558, 1995.

[39] CHAN, L.W., TAN, L.H., HENG, P.W. "Process analytical technology: application to particle sizing in spray drying”, AAPS PharmSciTech, v.9, n.1, pp.259-66, 2007.

[40] TEERANACHAIDEEKUL, V., SOUTO, E.B., JUNYAPRASERT, V.B., et al., “Cetyl palmitatebased NLC for topical delivery of Coenzyme Q (10) - development, physicochemical characterization and in vitro release studies", European Journal of Pharmaceutics and Biopharmaceutics, v.67, n.1, pp.141-8, 2007.

[41] NIJDAM, J. J., LANGRISH, T.A.J. "The effect of surface composition on the functional properties of milk powders", Journal of Food Engineering, v. 77, n. 4, pp. 919-925, Dec. 2006.

[42] SOARES, L.A.L. Obtenção de comprimidos contendo alto teor de produto seco por aspersão de Maytenus ilicifolia Mart. ex Reissek - Celastraceae. Desenvolvimento tecnológico de produtos intermediários e final, Tese de D.Sc., Programa de Pós-graduação em Ciências Farmacêuticas, UFRGS, Porto Alegre, RS, Brasil, 2002. 
[43] CAO, X.Q., VASSEN, R., SCHWARTZ, S., et al., "Spray-drying of ceramics for plasma-spray coating", Journal of the European Ceramic Society, v.20, n.14-15, pp. 2433-2439, Dec. 2000.

[44] VALENTE, B.R. "Desenvolvimento de comprimidos de liberação entérica contendo omeprazol", Dissertação de M.Sc., PGFar, UFSC, Florianópolis, SC, Brasil, 2010.

[45] AMBIKE, A.A., MAHADIK, K.R., PARADKAR, A. "Spray-dried amorphous solid dispersions of simvastatin, a low Tg drug: in vitro and in vivo evaluations", Pharmaceutical Research, v.22, n.6, pp. 990-998, Jun. 2005.

[46] QUEK, S.Y., CHOK, N.K., SWEDLUND, P. "The physicochemical properties of spray-dried watermelon powders", Chemical Engineering and Processing, v.46, n.5, pp. 386-392, May. 2007.

[47] BOHR, A, BOETKER, J.P., RADES, T., et al., "Application of spray-drying and electrospraying/electospinning for poorly water-soluble drugs: a particle engineering approach", Current Pharmaceutical Design, v. 20, n. 3, pp.325-348, 2014.

[48] AULTON, M.E. Delineamento de Formas Farmacêuticas, 2 ed, Porto Alegre, Artmed, 2005.

[49] PATEL, B.B., PATEL, J.C., CHAKRABORTYB, S., et al., "Revealing facts behind spray dried solid dispersion technology used for solubility enhancement", Saudi Pharmaceutical Journal, v.23, n.4, pp.352-365, Sep. 2014.

[50] MARTINS, R.M., MACHADO, M.O. PEREIRA, S.V., et al., "Microparticulated hydrochlorothiazide solid dispersion: Enhancing dissolution properties via spray drying", Drying Technology, v. 30, n. 9, pp. 959-967, May. 2012.

[51] TAKEUCHI, H., NAGIRA, S., YAMAMOTO, H., et al., "Solid dispersion particles of amorphous indomethacin with fine porous silica particles by using spray-drying method", International Journal of Pharmaceutics, v.293, n.1-2, p.155-164, Apr. 2005.

[52] SHEN, S.C., NG, W.K., CHIA, L. "Physical state and dissolution of ibuprofen formulated by cospray drying with mesoporous silica: effect of pore and particle size", International Journal of Pharmaceutics, v.410, n.1-2, p.188-195, May. 2011.

[53] MOLYNEUX, P. "The use of the stable free radical diphenylpicrylhydrazyl (DPPH) for estimating antioxidant activity", Songklanakarin Journal of Science and Technology, v.26, n. 2, pp. 211-216, 2004.

[54] KATSUBE, T., TSURUNAGA, Y., SUGIYAMA, M., et al., "Effect of air-drying temperature on antioxidant capacity and stability of polyphenolic compounds in mulberry (Morus alba L.) leaves", Food Chemistry, v.113, n.4, pp.964-969, 2009.

[55] MRKÌC, V., COCCI, E., ROSA, M.D., et al., "Effect of drying conditions on bioactive compounds and antioxidant activity of broccoli (Brassica oleracea L.)", Journal of the Science of Food and Agriculture, v. 86, n.10, pp.1559-1566, 2006.

[56] TANG, F.Y., SHIH, C.J., CHENG, L.H., et al., "Lycopene inhibits growth of human colon cancer cells via suppression of the Akt signaling pathway", Molecular Nutrition \& Food Research, v. 52, n. 6, pp. 646-654, 2008.

[57] BEN-DOR, A., STEINER, M., GHEBER L., et al., "Carotenoids activate the antioxidant response element transcription system”, Molecular Cancer Therapeutics, v.4, n.1, pp. 177-186, 2005.

[58] ZHANG, J., SUN, Z., SUN, P., et al., "Microalgal carotenoids: beneficial effects and potential in human health", Food \& Function, v.5, n.3, pp.413-25, Mar. 2014.

[59] CUI, Y., LU, Z., BAI, L., et al., "beta-Carotene induces apoptosis and up-regulates peroxisome proliferator-activated receptor gamma expression and reactive oxygen species production in MCF-7 cancer cells", European Jounal of Cancer, v.43, n.17, pp.2590-2601, Nov. 2007. 